\title{
Getting Customers' Motives: Lean on Motivation Theory for Designing Virtual Ideas Communities
}

\author{
Ulrich Bretschneider and Jan Marco Leimeister \\ Kassel University, Chair for Information Systems, Nora-Platiel-Str. 4, 34127 Kassel, Germany \\ Tel.: +49 (0) 5618042880 \\ \{bretschneider, leimeister\}@wi-kassel.de
}

\begin{abstract}
Virtual ideas communities such as Dell's "Ideastorm" or Intel's "Ideazone" are very popular in practice. In such communities distributed groups of individual customers focus on voluntarily sharing and elaborating innovative ideas to support company's new products development. However, a look at existing ideas community leads to the conclusion that many of them are featured to the minimum necessary. Typically, they fail to provide technical components and organizational arrangements that are able to motivate customers to submit ideas. Based on insights from motivation theory it is known that such components and arrangements could serve as incentives for submitting ideas, as they activate customers' corresponding motives, which again lead to idea submission. In reverse, this means when knowing customers different motives one can systematically derive adequate components and arrangements from it. The aim of this paper is to derive components from customers' motives. Our research approach is two-folded. First, we applied an online survey among participants of the SAPiens ideas community. We empirically queried motives that lead participants to submit ideas. After that we come up with an empirical tested set of six motives (self-marketing, fun, altruism, recognition, product improvement and enhancement as well as learning). Second, we used these six motives in order to derive a set of adequate components from it. Our research will deliver important examples and insights how to arrange virtual ideas communities with technical and organizational components and arrangements in order to make them more effective, so that more customers are willing to submit ideas.
\end{abstract}

Keywords: virtual ideas communities, open innovation, user motivation, customer integration, motives.

\section{Introduction}

\subsection{Open Innovation: Customer Integration into Innovation Activities}

In the 20th century, many leading industrial companies generated, developed and commercialized ideas for innovations in self-reliance. Nowadays, companies are increasingly rethinking the fundamental ways of managing their innovation activities. 
According to Chesbrough's open innovation paradigm, overcoming companies' boundaries in order to open up for other resources for innovation becomes more and more important (Chesbrough 2003). In this context customers are seen as one of the biggest resource for innovations. Customer integration into innovation activities is a strategy of value creation in which customers are taking part in innovation value creating activities. Customers respectively product users often have rather high product expertise as well as knowledge and creativity potential, which they gained by regular product usage. However, this customer's knowledge is hardly accessible for companies. When integrating customer into the product innovation process companies profit by getting access to customer's product know-how.

In particular, when integrating customers into the early stages of the product innovation process, which focuses on generating innovations ideas, companies tend to get access to customer innovation ideas. On the one hand, ideas expressed by customers reflect their needs and wishes. On the other hand these ideas can represent suggestions describing how ideas can be transferred into marketable products. These so called "need information" and "solution information" constitute valuable input for the product innovation process (von Hippel 1994).

In literature and practice certain methods for integrating customers into the early stages of the innovation process are discussed. Von Hippel's "Lead-User-Approach" is a popular example of this understanding of customer integration (von Hippel 1986). The Lead-User-Method implies systematic identification of single innovative customers, so-called lead users, and their integration into workshops in order to generate ideas and concepts for new products or services together with companies' employees.

In literature and practice ideas competitions are described as another familiar practice to get access to customer ideas. An ideas competition can be defined as an invitation of a company to its customer base in order to submit innovation ideas to a certain topic within a certain short timeline and typically via an Internet platform. An ideareviewers committee evaluates these contributions and selects the winner (Piller and Walcher 2006; Leimeister, Huber et al. 2009).

Recently, a novel method becomes relevant in practice. This alternative method can be constituted as "Virtual Ideas Communities". Ideas communities are initiated by companies and seek to offer customers a virtual forum for submitting innovation ideas. On the virtual community platform customers can post their ideas, vote for other participants' ideas and comment and/or discuss on other participants' ideas in order to help making ideas better in a collaborative manner.

While online user innovation communities in general are not a new phenomenon, as at least the open source software phenomenon demonstrates, with ideas communities there is an underlying difference. Firms run idea communities - from initial community building until continuous community management. This allows them to control the community in total and because of this to use its idea outcome nonrestrictively. In contrast to that, so far known online user innovation communities, like open source communities or online communities of enthusiasts in basketball that share ideas for improving the design or other features of sport shoes (Füller, Jawecki et al. 2007), are run completely by and for users, which made it difficult for firms harnessing communities' outcome for new product development. 
So, ideas communities, which we define as distributed groups of individual customers focused on sharing and elaborating innovation ideas supported by computer mediated community platforms as well as initiated and run by firms, are an emerging popular strategy in order to gain ideas for innovations from customers. Companies like Google, Intel, BMW, SAP, or Acrobat are only a few examples that run ideas communities.

\subsection{Theoretical Background: Motivation Theory}

Motivation psychology differentiates between the notion "motive" and "motivation". A motive is seen as an individual's psychological disposition (von Rosenstiel 2003). This disposition describes how important certain goals for an individual are. Some motives are inborn but a relatively stable set of motives is developed during an individual's socialization process (Heckhausen and Heckhausen 2006). This set of motives constitutes an individual's cognitive subsystem. Motivation describes the process how an individual's motives become activated. The basic principle of motivation is characterized in motivation psychology as follows: In a particular situational context, an adequate motive will be activated and subsequently cause certain behaviour. In such situational contexts certain things, that an individual perceives, will serve as incentive that stimulates corresponding motives. So motives can be seen as incitement to human act and behaviour (von Rosenstiel 2003). Von Rosenstiel (von Rosenstiel 2003) illustrates the activation of human behaviour in a simple model, shown in the following figure.

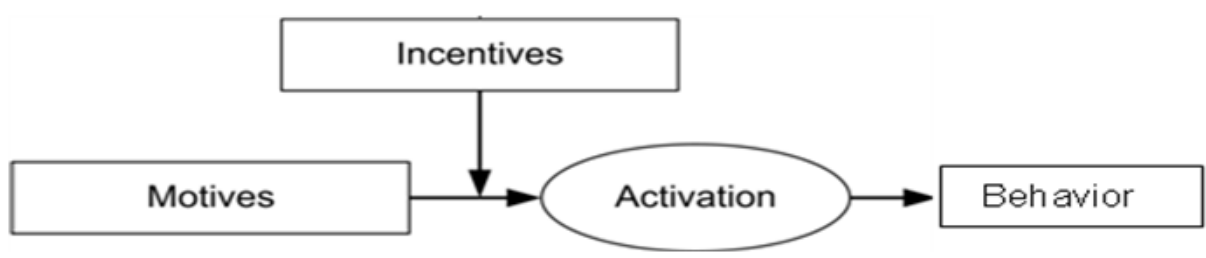

Fig. 1. Motivation model, adapted from Von Rosenstiel (2003)

One can distinguish between intrinsic and extrinsic motivation: There are certain activities and behaviors that some people naturally engage in, such as eating or drinking. Deci calls this intrinsic motivation, because the underlying motives are stimulated by an inborn feeling, such as hunger or thirst, not by a situational context as described above (Deci and Ryan 1985). Beside the motives that belong to the class of internal motivation there are several other motives, which do not arise from an individual's inborn desire. They arise directly from external stimuli that are perceived from above mentioned situational context. These motives can thus be categorized into the class of so called external motives (Deci and Ryan 1985). 
For our research one can draw on this motivation model. So, adapted to the case of ideas communities certain components of ideas communities can be interpreted by a customer as a mentioned incentive that again activates this person's individual corresponding motive and then finally lead to idea submission.

\subsection{Research Aim, Approach, and Methodology}

Many ideas community offer only a limited range of attractive components, such as technical functionalities, tools or organizational arrangements. Typically, ideas communities only offer three, technical based core-elements. These are IT-based systems for idea up-loading, idea commenting, and idea evaluating. Certainly, the lack of attractive components and arrangements is a main reason why most ideas communities count only few ideas. However, providing more attractive components is the manipulating variable that firms can use in order to influence customers' willingness for idea submission, as can be learned from above mentioned motivation theory.

So, our research aimed at identifying much more attractive components and arrangements for virtual ideas communities than existing core elements. The underlying approach of our research in accordance to the above described motivation model is as follows: Knowing customers' motives one is able to determine adequate components and arrangements that serve as incentives for stimulating theirs corresponding motives and than in turn will make them submit ideas in a much more willing manner.

So, our research seeks to deliver technical- as well as organizational-based components and arrangements that are able to raise idea output in ideas communities. As Schneiderman (Shneiderman 2000) emphasized the necessity of efficient environments enabling innovation and creativity processes in the scope of customer integration, our findings will contribute for designing such effective environments within idea communities.

Our research approach is two-folded. First, we applied an online survey among participants of the SAPiens idea community. We empirically queried motives that generally lead SAPiens participants to submit ideas. After that we come up with an empirical tested set of six motives (self-marketing, fun, altruism, recognition, product improvement and enhancement as well as learning). Second, we used these six motives in order to derive a set of adequate components and arrangements from it.

\subsection{Case Background: The SAPiens Ideas Community}

SAPiens is an Internet based ideas community (www.sapiens.info) initiated and run by the ERP software producer SAP. SAPiens was launched in summer 2009 and targeted users of SAP software. Each submitted idea, phrased in an average length of five-line phrases, was visualised in an idea pool, a separate section of the online platform. Figure 2 shows the homepage of the SAPiens ideas community.

Until March 2010156 SAP users became registered members of the SAPiens community. Of those users, 149 actively participated by submitting at least one idea. The rest participated by just scoring and commenting submissions of other users or simply lurk. The comments and user evaluations helped the ideas presenters to refine their ideas. 


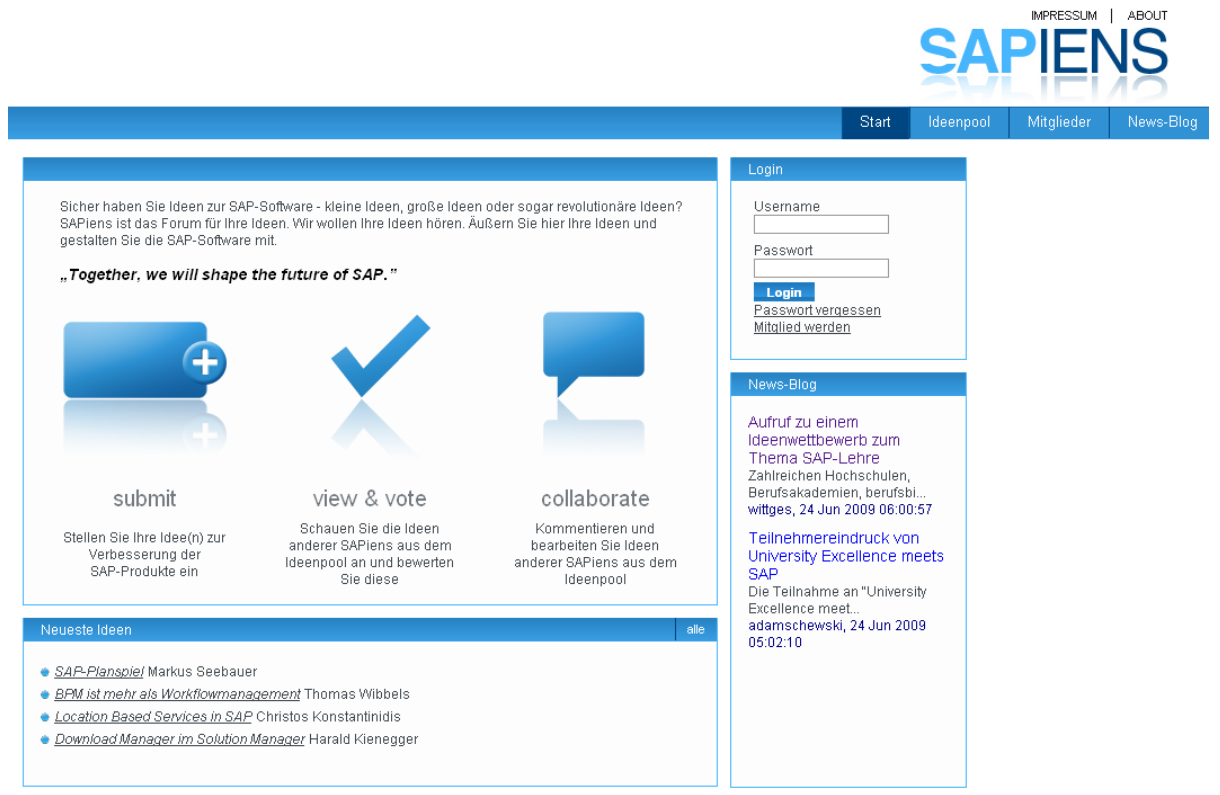

Fig. 2. Homepage of the SAPiens ideas community

\section{Motives of Sapiens' Members}

In order to research motives that make SAPiens members submitting ideas we query a set of eleven possible and adequate operationalized motives among SAPiens members with the help of an online survey. Before that, we extracted queried motives from an extensive literature review. After data collection we analysed empirical data with the help of factor analysis. All results are presented in the following sections.

\subsection{Literature Review}

Human motivation has been discussed prominently in the field of open source community research. Various motives are examined that make open source software programmers participate in open source software projects. As open source software communities are basically comparable to ideas communities it is worth to check if motives examined in the open source domain could be extracted to our case. So we conducted a literature review. We examined six empirical studies out of the field of open source research that deal with programmers' motives for participation in open source communities. We focused on its examined motivation factors and analyzed which of them are appropriable for the use of our own survey. Based on the insights of this research we applied 11 motives, which are briefly described as follows.

The first motive is fun. Fun is a prominent motive studied in several open source motivation studies, e.g., Hars and Ou (Hars and Ou 2002), Lakhani and Wolf (Lakhani and Wolf 2005), and Osterloh et al. (Osterloh, Rota et al. 2002). In open source context, the fun motive is described as having fun or enjoying one-self when 
programming. Applied to ideas communities the fun motive is manifested in having fun in developing ideas.

The second motive out of the class of intrinsic motivation is intellectual stimulation. Raymond describes programmers who are motivated by this factor for engaging in open source communities as people "...who enjoys the intellectual challenge of creatively overcoming or circumventing limitations" (Raymond 1996). In their study Lakhani and Wolf (Lakhani and Wolf 2005) found out that the top single reason to contribute to open source projects is based on intellectual stimulation. Applied to ideas communities developing ideas for participants is intellectually stimulating.

An important motive considered in studies that explore motivations of open source software programmers is "altruism", e.g., Hars and Ou (Hars and Ou 2002). Open source software programmers who are motivated by altruism seek to increase the welfare of the open software community by writing program code without expecting any reward. Altruism can be interpreted as the direct opposite to selfishness or as "doing something for another at some cost to oneself" (Ozinga 1999). Altruism can also be presumed to be a driver that motivates customers to participate in ideas communities.

Another intrinsic motive considered in open source motivation studies is "reciprocity". Shah (Shah 2005) as well as Lakhani and Wolf (Lakhani and Wolf 2005) found out that some open source programmers participate because they felt a sense of obligation to give something back to the open source community in return for the software tools it provides. This motive could also be assigned to the case of customer participation in ideas communities. So, some customer may feel obliged to SAP in return for the use of the SAP software.

One motive out of the class of external motives is the so called recognition, e.g., Hars and Ou (Hars and Ou 2002) or Hertel et al. (Hertel, Niedner et al. 2003). Recognition contains expected reactions of significant others, such as other programmers. Motivation to contribute to a open source community should be higher the more positive the expected reactions of significant others are, weighted by the perceived importance of these significant others. This relation is formally expressed as a multiplicative function. Applied to ideas communities participants expect positive reactions from other participants as well as the organizer. These reactions by thirds may be caused by the submitted ideas displayed on the Internet platform.

Furthermore, people may consider participating in ideas communities as an effective way to demonstrate their capabilities and skills shown through their submitted ideas. Their achievements in ideas communities can be used to demonstrate competence to the organizer of the ideas community or others. Reactions by thirds may be caused on the basis of submitted ideas. Participating in ideas community, therefore, can be a good channel for self-advertisement for those seeking new job opportunities, for example. This phenomenon is mainly discussed in the field of researching motivations of open source programmers as self-marketing motive, e.g., Hars and Ou (Hars and $\mathrm{Ou}$ 2002) or Hertel et al. (Hertel, Niedner et al. 2003).

In the context of open source communities identification is examined also as a motivational factor. Identification is a reason for programmers engaging in open source communities when other participants sharing someone's aims, ideals, etc. (Hars and Ou 2002; Osterloh, Rota et al. 2002; Hertel, Niedner et al. 2003; Lakhani and Wolf 
2005). Kelly and Breinlinger (Kelly and Breinlinger 1995) as well as Simon et al. (Simon, Loewy et al. 1998) used identification in order to explain why people engage in social movements of specific social groups such as older people, women, etc. Applied to ideas communities, people may regard for participating because they feel aligned to the organising firm of the ideas community in a manner that marketing science characterizes as customer's brand loyalty or company awareness (Aaker 1997). So, identification with the organizing firm is a motivational factor worth to be include to our survey.

Insights from open source motivation research reveal that many open source programmers participate in open source projects because of their willing to improve functionality of the software or failures in the lines of code (Hars and Ou 2002). This could be also relevant for participants of ideas communities. By submitting an idea participants may accentuate the necessity for improving the functionality or a defect of the underlying product. So, product improvement is a motivational factor worth to be include to our survey.

Furthermore, in the open source software research the need motive is discussed. As several studies, e.g., Gosh et al. (Ghosh, Glott et al. 2002) reveal that programmers engage in open source communities because they have a personal need or just detect a need for a certain kind of software. They appeal to an existing community or even form a new open software community in order to implement their need. Applied to the SAPiens ideas community customers may motivate to submit an idea because they detect a certain personal need which they phrase into an idea. So, the need motive seems to be worth included in our study.

Another motive out of the class of extrinsic motivation is learning. Learning is also discussed in the field of open source motivation research. Hars and Ou (Hars and Ou 2002) found out that some open source programmers are motivated for participating in open source projects by the prospect of selecting learning experiences. This motivation factor can be adopted for the present study. So, customers may also participate in ideas communities to expand their personal skills, capabilities, and knowledge.

Different open source motivation studies found out that open source software programmers also seek for contacts to peers in order to make new friends or socialize with others (Hertel, Niedner et al. 2003). When applied to ideas communities we expect that customer also have this motive to contribute to ideas communities.

\subsection{Survey}

The survey seeks to explore the motives that make participants of the SAPiens ideas community contribute ideas. Since perceived motivation-related issues can be best expressed by the participants of the SAPiens community themselves, we conducted a standardized questionnaire survey. 29 items were formulated in order to measure the 11 motives (see table 1). Using a rating scale ranging from 1 (strongly disagree) to 5 (strongly agree), participants were asked to rate the degree to which extent each motive makes him or her submitting ideas to the SAPiens ideas community. 
Table 1. Adapted motives

\begin{tabular}{ll}
\hline Motive & Reference \\
\hline Fun & $\begin{array}{l}\text { Contextualized from Hars/Ou (2002); Hertel/Niedner/Herrmann } \\
(2003) ; \text { Lakhani/Wolf (2005); Shah (2005). }\end{array}$ \\
\hline Intellectual stimulation & Contextualized from Lakhani/Wolf (2005). \\
\hline Altruism & Contextualized from Hars/Ou (2002); Shah (2005). \\
\hline Reciprocity & $\begin{array}{l}\text { Contextualized from Ghosh et al. (2002); Lakhani/Wolf (2005); } \\
\text { Shah (2005). }\end{array}$ \\
\hline Recognition & $\begin{array}{l}\text { Contextualized from Ghosh et al. (2002); Hars/Ou (2002); } \\
\text { Hertel/Niedner/Herrmann (2003); Lakhani/Wolf (2005); Shah } \\
\text { (2005). }\end{array}$ \\
\hline Identifying with the & $\begin{array}{l}\text { Developed in this research by building on Hars/Ou (2002); } \\
\text { Hertel/Niedner/Herrmann (2003); Lakhani/Wolf (2005); } \\
\text { Osterloh/Rota/Kuster (2002). }\end{array}$ \\
\hline Product improvement & $\begin{array}{l}\text { Contextualized from Ghosh et al. (2002); Her- } \\
\text { tel/Niedner/Herrmann (2003); Shah (2005). }\end{array}$ \\
\hline Need & $\begin{array}{l}\text { Contextualized from Ghosh et al. (2002); Hars/Ou (2002); } \\
\text { Lakhani/Wolf (2005); Shah (2005). }\end{array}$ \\
\hline Learning & $\begin{array}{l}\text { Contextualized from Ghosh et al. (2002); Hars/Ou (2002); } \\
\text { Hertel/Niedner/Herrmann (2003); Lakhani/Wolf (2005). }\end{array}$ \\
\hline Contextualized from Ghosh et al. (2002); Her- \\
tel/Niedner/Herrmann (2003).
\end{tabular}

Table 2. Rotated component matrix

\begin{tabular}{|c|c|c|c|c|c|c|}
\hline \multirow{2}{*}{$\begin{array}{l}\text { Items } \\
\text { I attended the SAPiens } \\
\text { ideas community } \\
\text { because... }\end{array}$} & \multicolumn{6}{|c|}{ Components } \\
\hline & 1 & 2 & 3 & 4 & 5 & 6 \\
\hline & & 1. & Fun & & & \\
\hline $\begin{array}{l}\text {... I have fun in working } \\
\text { out ideas and creative } \\
\text { solutions. }(S 1)\end{array}$ & 0.065 & $\underline{0.660}$ & 0.268 & 0.065 & 0.117 & -0.039 \\
\hline $\begin{array}{l}\text {... I perceive composing } \\
\text { creative ideas as a kind } \\
\text { of self-realization. }(S 2)\end{array}$ & 0.043 & $\underline{0.630}$ & 0.026 & 0.209 & 0.325 & 0.176 \\
\hline $\begin{array}{l}\ldots \text { I take much pleasure } \\
\text { in being creative. }(S 3)\end{array}$ & 0.255 & $\underline{0.785}$ & 0.203 & 0.107 & 0.118 & 0.030 \\
\hline \multicolumn{7}{|c|}{ Intellectual stimulation } \\
\hline $\begin{array}{l}\text {... I'm stimulated by } \\
\text { generating creative } \\
\text { ideas. }(I H I)\end{array}$ & \multicolumn{6}{|c|}{ excluded as item did not achieve critical MSA value } \\
\hline
\end{tabular}


Table 2. (Continued)

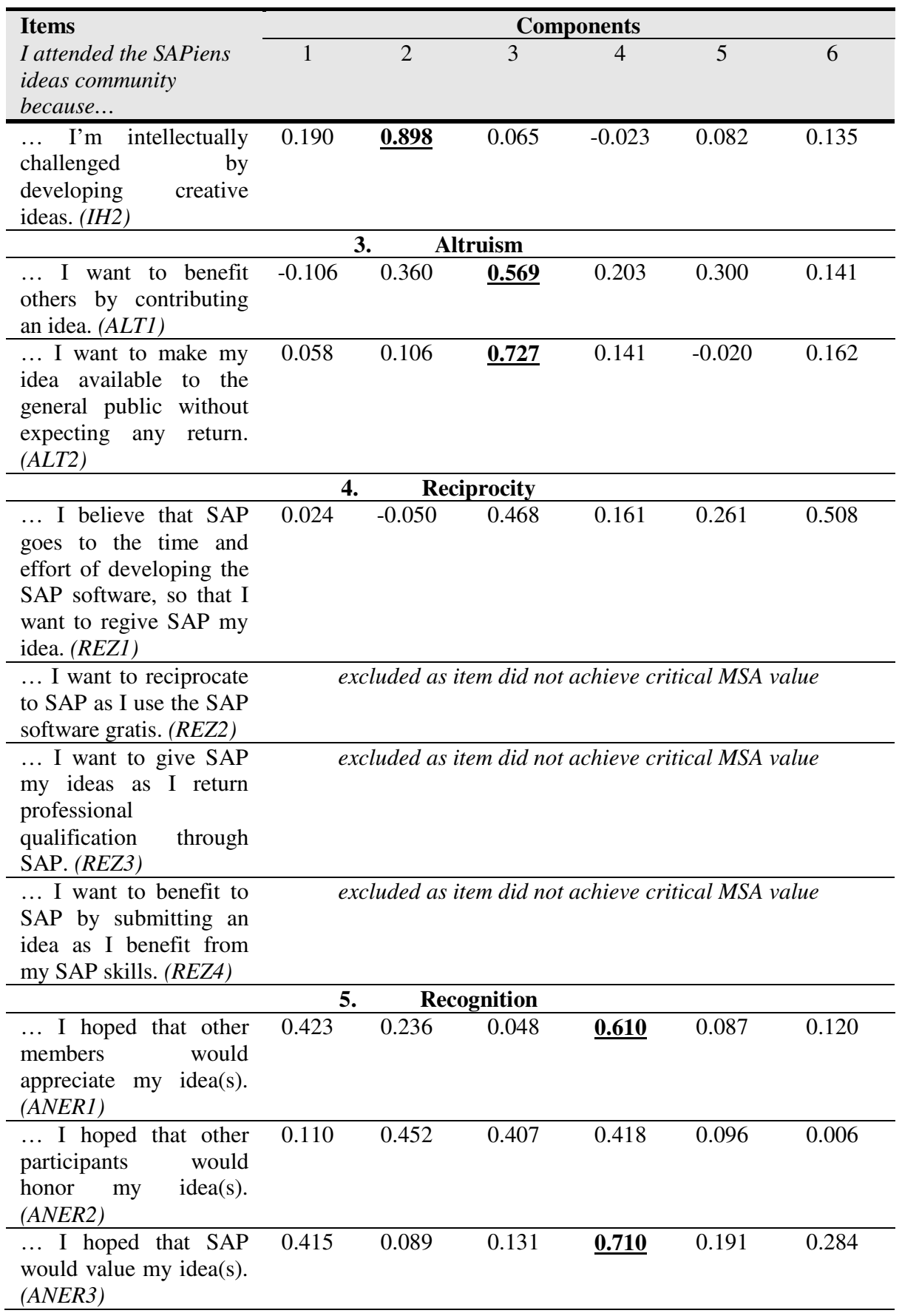


Table 2. (Continued)

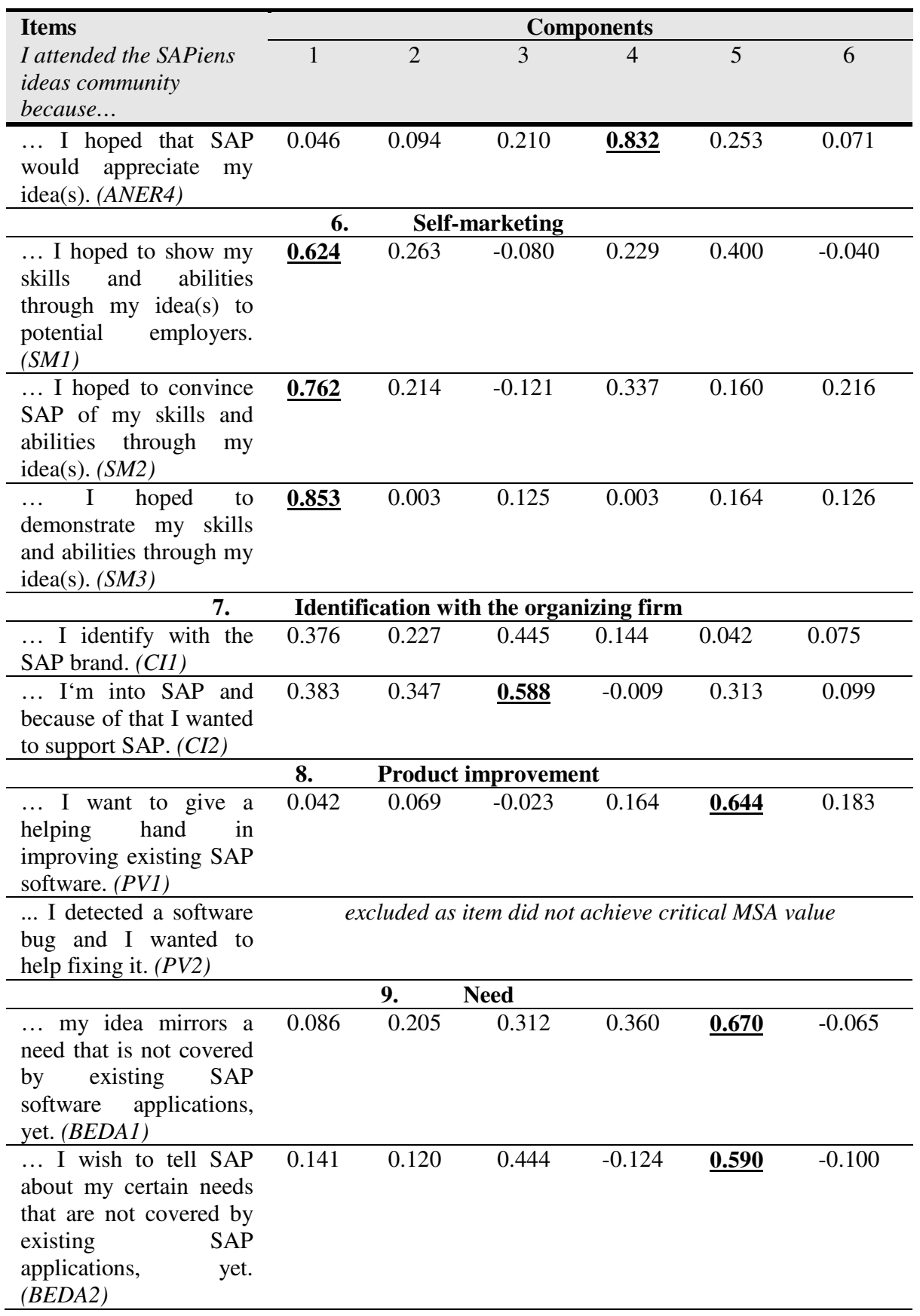


Table 2. (Continued)

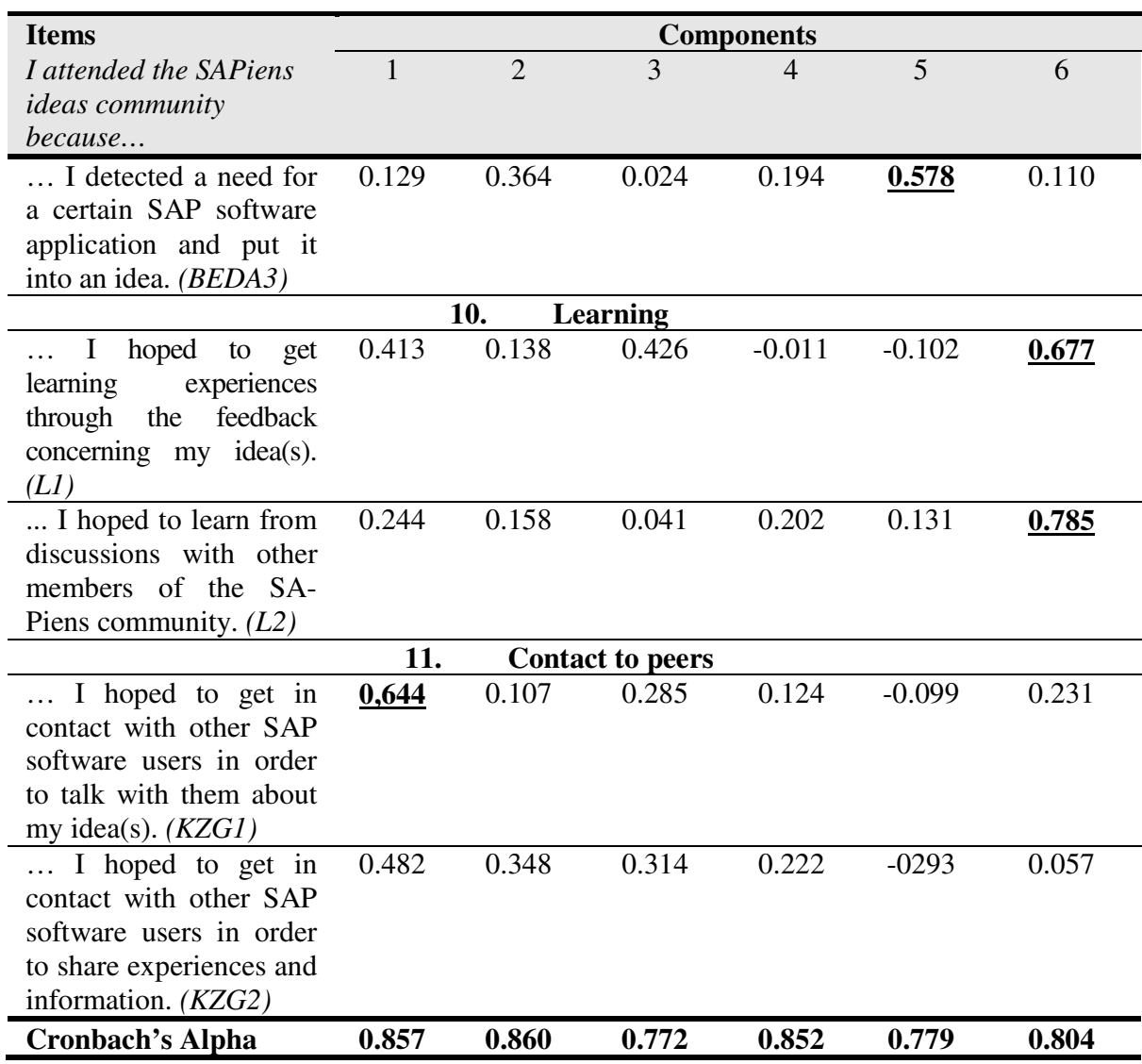

The questionnaire used in this study was structured, tested and consequently adapted to the needs of the target audience. The questionnaire was pre-tested by 10 experts pursuing doctoral and Master's degrees in information technology and business administration. The objectives of the pre-test were to ensure that none of the items were ambiguous as well as that the items adequately captured the domain of interest. Expert opinions' indicated that the content of the items was valid.

We run the online survey in March 2010. The questionnaire was implemented using the online-survey service "2aks". Each participant of the SAPiens ideas community that submitted at least one idea $(\mathrm{N}=149)$ was provided with a personalized link to the online survey by eMail. The survey was administered over a period of four weeks. Eighty-seven participants provided adaptable answers to the questionnaire which represents a $58.39 \%$ response rate. $70.11 \%$ of those adaptable answers were men $(\mathrm{n}=$ 61). $60.92 \%(n=53)$ of those adaptable answers were between 20 and 30 years old. As it concerns the occupation of these participants, with $55.17 \%(n=48)$ students were overrepresented in the sample. The rest were either SAP consultants or persons in charge that work with SAP applications once a day or at least a few times a week. 


\subsection{Results}

We tested construct validity of our 11 motives and related 29 items based on an exploratory factor analysis. We analyzed the items with the help of the statistical software program SPSS 17.0. In order to check whether the data was appropriate for factor analysis we pre-analyzed the Measures of Sampling Adequacy (MSA) for the whole data structure as well as for individual items. The items REZ2, PV2, IH1, REZ4 as well as REZ3 showed MSA values that were lower 0.5. According to Cureton and D'Agostion's recommendation, who deemed that items achieve sampling adequacy if values are equal or exceed the criterion of 0.5 (Cureton and D'Agostino 1983), these items were excluded within six iterations. After the sixth iteration all remaining items were above 0.6 and exploratory factor analysis was applicable. Furthermore, we pre-checked the global MSA value after the sixth iteration in order to ensure applicability of explorative factor analysis. With a MSA of 0.729 Cureton and D'Agostion's (Cureton and D'Agostino 1983) stringent 0.5-criteria was met, too.

The factor analysis resulted in six factors with eigenvalues higher 1 (varimax rotation). All the six factors explain a total of $66.321 \%$ variance. The first factor explained $14.149 \%$ variance. It was mostly determined by all items that represent the expected motive self-marketing as well as the item KZG1. As the intention to seek for peers in order to get in contact can be seen as an assumption for self-marketing activities as well as peers constitutes the target audience of self-marketing activities the KZG1 loading on this factor can be accepted plausible. Because of this, we will call this factor as "self-marketing" (component 1 in figure 5). The second factor explained $13.887 \%$ variance and mostly was determined by all "fun" items. Furthermore, the item IH2 also loads on this factor. As intellectual stimulation can be interpreted as a form of fun we will accept including this item in factor 2. Following this argumentation we will call this factor "fun" (component 2 in table 2).

The items ALT1 and ALT2 as well as CI2 load on another factor, which explained $11.066 \%$ variance. As altruistic feelings only will be brought toward a certain person or organization with whom or which one can identify this seems plausible. Thus, the third factor can be called "altruism" (component 3 in table 2). On the fourth factor load 3 items that expected to explain "recognition" (component 4 in table 2), solely (10.040\% variance).

The fifth factor, which represents a $9.989 \%$ expression of variance, we call "product improvement and enhancement" (component 5 in table 2) as all need items as well as one of two product improvement items load on it. Finally, the sixth factor which explained additional $7.190 \%$ variance was mostly determined by the supposed learning items. As supposed, learning (component 6 in table 2) seemed to be an independent motive.

The items REZ1, ANER2, CI1 as well as KZG2 were excluded as their values are $<0.55$ according to Hair et al.'s recommendation, who deemed that items achieve acceptable factor loadings if values are equal or exceed the criterion of 0.55 (Hair, Anderson et al. 1998). After this complex explanatory factor analysis its results support the contention that our model has adequate construct validity.

The reliability of the resulting factors was checked using Cronbach's alpha. A Cronbach's alpha of 0.7 or higher (Nunnally 1978) was used as an acceptable value for internal consistency of the measure. The Cronbach's alphas of the four factors 
range from 0.772 to 0.860 (compare table 2). These values support the contention that all the factors had adequate reliability.

As examination of validity as well as reliability of an underlying research model by solely applying explanatory factor analysis respectively Cronbach's alpha do not meet modern requirements (Bogazzi, Yi et al. 1991), according to Homburg and Giering's recommendation (Homburg and Giering 1996) we secondly tested our new model, based on its six remaining factors and its corresponding 20 items, by applying confirmatory factor analysis and using Amos 18.0. First, we checked the global fit of the new model. The Goodness of Fit Index (GFI) was 0.951 and the Adjusted Goodness of Fit Index (AGFI) was 0.933. These indices were well over the under threshold of 0.9, which indicates an adequate fit (Browne and Cudeck 1993). In order to check

Table 3. Values for Individual Item Reliability, Composite Reliability, and AVE

\begin{tabular}{|c|c|c|c|c|}
\hline Factor & Item & $\begin{array}{c}\text { Individual Item } \\
\text { Reliability } \\
(>/=0.4)\end{array}$ & $\begin{array}{c}\text { Composite } \\
\text { Reliability } \\
(>/=0.6)\end{array}$ & $\begin{array}{c}\text { AVE } \\
(>/=0.5)\end{array}$ \\
\hline \multirow[t]{4}{*}{ Self-Marketing } & MO_SM_1 & 0.557 & \multirow{4}{*}{0.860} & \multirow{4}{*}{0.608} \\
\hline & MO_SM_2 & 0.800 & & \\
\hline & MO_SM_3 & 0.564 & & \\
\hline & MO_KZG_1 & 0.503 & & \\
\hline \multirow[t]{4}{*}{ Fun } & MO_S_1 & 0.433 & \multirow{4}{*}{0.871} & \multirow{4}{*}{0.639} \\
\hline & MO_S_2 & 0.577 & & \\
\hline & MO_S_3 & 0.828 & & \\
\hline & MO_IH_2 & 0.647 & & \\
\hline \multirow[t]{3}{*}{ Altruism } & MO_ALT_1 & 0.490 & \multirow{3}{*}{0.778} & \multirow{3}{*}{0.552} \\
\hline & MO_ALT_2 & 0.493 & & \\
\hline & MO_CI_2 & 0.881 & & \\
\hline \multirow[t]{3}{*}{ Recognition } & MO_ANER_1 & 0.677 & \multirow{3}{*}{0.860} & \multirow{3}{*}{0.676} \\
\hline & MO_ANER_3 & 0.927 & & \\
\hline & MO_ANER_4 & 0.424 & & \\
\hline \multirow{4}{*}{$\begin{array}{l}\text { Product Im- } \\
\text { provement and } \\
\text { Enhancement }\end{array}$} & MO_BEDA_1 & 0.725 & \multirow{4}{*}{0.781} & \multirow{4}{*}{0.574} \\
\hline & MO_BEDA_2 & 0.427 & & \\
\hline & MO_BEDA_3 & 0.647 & & \\
\hline & MO_PV_1 & 0.418 & & \\
\hline \multirow[t]{2}{*}{ Learning } & MO_L_1 & 0.725 & \multirow{2}{*}{0.698} & \multirow{2}{*}{0.536} \\
\hline & MO_L_2 & 0.626 & & \\
\hline
\end{tabular}


reliability of the model, we measured all Individual Item Reliabilities, which exceeded the minimum threshold of 0.4 (Homburg and Giering 1996). Hence, good reliability is confirmed (compare table 3 ).

Furthermore, all factors of our new model showed good values for Composite Reliabilities as well as good values for Average Variance Explained (AVE), so that convergent validity can be assumed (compare table 3 ). Values of 0.6 regarding the Composite Reliability and 0.5 for the AVE can be seen as minimum values for indicating a good measurement quality (Bagozzi and Yi 1988). The discriminant validity of the factors was checked by using the Fornell-Larcker criteria, which claims that one factor's AVE should be higher than its squared correlation with every other factor (Fornell and Larcker 1981). Tables 3 and 4 depict that discriminant validity can be assumed for the six factors of our new model.

Table 4. Squared Multiple Correlations

\begin{tabular}{lcccccc}
\hline \multicolumn{7}{c}{ Squared Multiple Correlations } \\
\hline & $\begin{array}{c}\text { Self- } \\
\text { Marketing }\end{array}$ & Fun & Altruism & $\begin{array}{c}\text { Recog } \\
\text { nition }\end{array}$ & $\begin{array}{c}\text { Prod Imp + } \\
\text { Enh }\end{array}$ & Learning \\
\hline $\begin{array}{l}\text { Self- } \\
\text { Marketing }\end{array}$ & & 0.00289 & 0.0729 & 0.2401 & 0.0729 & 0.2704 \\
\hline Fun & 0.0289 & & 0.0324 & 0.0225 & 0.00289 & 0.0324 \\
\hline Altruism & 0.0729 & 0.0324 & & 0.0729 & 0.1156 & 0.1444 \\
\hline Recognition & 0.2401 & 0.0225 & 0.0729 & & 0.1089 & 0.2116 \\
\hline $\begin{array}{l}\text { Prod Im + } \\
\text { Enh }\end{array}$ & 0.0729 & 0.00289 & 0.1156 & 0.1089 & & 0.0441 \\
\hline Learning & 0.2704 & 0.0324 & 0.1444 & 0.2116 & 0.0441 & \\
\hline
\end{tabular}

\section{Deriving Components for Virtual Ideas Communities}

The purpose of our motivation study was to explore customers' motives for submitting ideas to the SAPiens idea community. Overall, the results suggest that there are six motives (self-marketing, fun, altruism, recognition, product improvement and enhancement as well as learning). In this section we exemplary use four of these six motives in order to derive adequate technical and organizational components and arrangements from it. Our research will deliver important examples and insights how to arrange virtual ideas communities with more attractive technical and organizational components and arrangements in order to make them more effective, so that more customers are willing to submit ideas.

First of all, we detected "Self-Marketing" as a significant motive. Because of this, organizers of ideas communities should procure possibilities that optimally display and represent participants' skills and capabilities. For example, implementing a profile site for every participant on the Internet platform of an ideas community - that displays participants' vita, competencies etc. as known from social network communities like Xing - would be fruitful in this context.

As our results show, the motive "Recognition" also was relevant. This suggests that organizers should play an active part in ideas communities and get in contact with 
participating customers, for example by commenting or giving positive feedback to participants' ideas, or praising participants' ideas as much as possible. In order to display positive reactions by the firm, organizers should assign "trophies" for customers' contributions by branding high quality ideas with a star, for example. These collectible achievements may more likely cause again positive reactions from other participants of the community. In order to get recognition from other participants rating systems would be fruitful. With the help of rating systems other users can quickly leave their opinions on ideas, for example by labeling a row of stars on which users can rate each idea.

Our findings reveal "Learning" as a relevant motive, too. That means that customers also participate in ideas communities in order to expand their personal skills, capabilities, and knowledge. So, in order to raise the likelihood of ideas submissions organizers should implement environments, where participants can select learning experiences when developing ideas. For example, coining mentors or tutors assisting participants actively in developing or elaborating ideas would be a possible measure in this context.

In light of the motives "Recognition" as well as "Learning" it is also important to implement an atmosphere of cooperation amongst the members of the community, not only because the principle goal of ideas communities is that its members discuss and enhance innovation ideas. An atmosphere of interpersonal cooperation will also raise members' willingness to give recognition to other participants as well as members' willingness to share learning experiences to other participants. When there is any kind of competitive culture on the other side, as it can be observed in ideas competitions, it will cause a non-cooperative behavior and may even cause a schism within the community. So, in order to implement a collaborative culture the organizers have to take appropriate organizational measures in the scope of current community management.

Furthermore, when building and running ideas communities firms should take into account that fun is an important motive that leads to ideas submission. Thus, firms have to establish organizational structures or design artifacts that serve customers' fun during an individual's process of generating ideas. For example, external mentors that will support participants in the manner of a ghost-writer would be an adequate design element in this context. Furthermore, the community platform should offer a personal site where members can display their collection of ideas. Spending time in creating ideas, managing, sharing, and curating the individual collection will give pleasure to the members. Furthermore, in terms of the recognition motive the owner's individual ideas collection is validated and recognized when other members comment, rate or even just view the displayed ideas in the collection. Furthermore, such an ideas collection can serve as self-marketing tool as the displayed ideas mirrored indirectly owner's competences, creativity potential etc. In this context, owners may be seen as an expert in the area of interest, which enhances its reputation and in turn increases the likelihood of submitting more ideas of good quality.

\section{Future Research and Limitations}

Our results provide only a few examples for components that can be derived from our empirical tested motives. Certainly, there are a lot more to explore. As these components are derived by plausibility efforts, they have to be evaluated in a further step. 
Only when tested empirically one can make sure that hypothetically derived components are really leading to idea submissions. So, future research has to develop and apply empirical tests that prove effectiveness of each component in accordance to its corresponding motive.

One of the major limitations of this study involves the sample of the motivation survey. First, the sample size was relatively small. Despite the fact that the size was absolutely adequate for applied factor analysis as well as regressions analysis our results would be more meaningful with a higher sample size. Second, the proportion of students included in the sample is relatively high. Despite the fact that students can be considered as users of the SAP software applications, our results might impose some limitations concerning the generalizability. Future research should test and validate the model by collecting more data sets as well as data from a different composition of subjects consisting of more "typically" SAP users, like SAP consultants or accounting clerks working with SAP applications.

\section{References}

Aaker, J.: Dimensions of Brand Personality. Journal of Marketing Research 34(3), 347-356 (1997)

Bagozzi, R.P., Yi, Y.: On the evaluation of Structural Equatation Models. Journal of the Academy of Marketing Sciences 16(1), 74-94 (1988)

Bogazzi, R., Yi, Y., et al.: Assessing Construct Validity in Organizational Research. Administrative Science Quarterly 36, 421-458 (1991)

Browne, M.W., Cudeck, R.: Alternative ways of assessing model fit. In: Bollen, K.A., Long, J.S. (eds.) Testing Structural Equation Models. Sage, Newbury Park (1993)

Chesbrough, H.: The era of open innovation. Sloan Management Review 44(4), 35-41 (2003)

Cureton, E.E., D’Agostino, R.B.: Factor Analysis: An Applied Approach. Hillsdale, New Jersey (1983)

Deci, E.L., Ryan, R.M.: Intrinsic Motivation and Self-Determination in Human Behavio. Springer, Heidelberg (1985)

Fornell, C., Larcker, D.F.: Evaluating Structural Equation Models with Unobservable Variables and Measurement Error. Journal of Marketing Research 18(2), 39-50 (1981)

Füller, J., Jawecki, G., et al.: Innovation Creation by online Basketball communities. Journal of Business Research 60(1), 60-71 (2007)

Ghosh, R.A., Glott, R., et al.: The Free/Libre and Open Source Software Developers Survey and Study - FLOSS, International Institute of Infonomics, University of Maastricht (2002)

Hair, J.F., Anderson, R.E., et al.: Multivariate Data Analysis. Prentice-Hall, Upper Saddle River, NJ (1998)

Hars, A., Ou, S.: Working for free? Motivations for participating in open-source projects. International Journal of Electronic Commerce 6(3), 25-39 (2002)

Heckhausen, J., Heckhausen, H.: Motivation und Handeln. Springer, Heidelberg (2006)

Hertel, G., Niedner, S., et al.: Motivation of software developers in open source projects: An internet-based survey of contributors to the Linux kernel. Research Policy 32(1), 1159-1177 (2003)

Homburg, C., Giering, A.: Konzeptionalisierung und Operationalisierung komplexer Konstrukte: Ein Leitfaden für die Marketingforschung. Marketing Zeitschrift für Forschung und Praxis 18(1), 5-24 (1996) 
Kelly, C., Breinlinger, S.: Identity and injustice: exploring women's participation in collective action. Journal of Community and Applied Social Psychology 5, 41-57 (1995)

Lakhani, K.R., Wolf, B.: Why Hackers Do What They Do. Understanding Motivation and Effort in Free/Open Source Software Projects. In: Feller, J., Fitzgerald, B., Hissam, S., Lakhani, K.R. (eds.) Perspectives on Free and Open Source Software. The MIT Press, Cambridge (2005)

Leimeister, J.M., Huber, M., et al.: Leveraging Crowdsourcing: Activation-Supporting Components for IT-Based Ideas Competitions. Journal of Management Information Systems 26(1), 197-224 (2009)

Nunnally, J.C.: Psychometric Theory, New York (1978)

Osterloh, M., Rota, S., et al.: Open Source Software Production: Climbing on the Shoulders of Giants, MIT Working Paper. MIT, Cambridge (2002)

Ozinga, J.: Altruism. Praeger, Westport (1999)

Piller, F.T., Walcher, D.: Toolkits for Idea Competitions: A Novel Method to Integrate Users in New Product Development. R\&D Management 36(3), 307-318 (2006)

Raymond, E.S.: The New Hacker's Dictionary. The MIT-Press, Cambridge (1996)

Shah, S.K.: Motivation, Governance \& the Viability of Hybrid Forms in Open Source Software Development, Working Paper, University of Washington (2005)

Shneiderman, B.: Creating Creativity: User Interfaces for Supporting Innovation. ACM Transactions on Computer-Human Interaction 7(1), 114-138 (2000)

Simon, B., Loewy, M., et al.: Collective identification and social movement participation. Journal of Personality and Social Psychology 74, 646-658 (1998)

von Hippel, E.: Lead users: a source of novel product concepts. Management Science 32(7), 791-805 (1986)

von Hippel, E.: Sticky information and the locus of problem solving. Management Science 40(4), 429-439 (1994)

von Rosenstiel, L.: Grundlagen der Organisationspsychologie. Schäffer-Poeschel, Stuttgart (2003) 